\title{
The endoscopic loop-and-let-go technique for treatment of an exceedingly rare cause of recurrent biliary pain
}
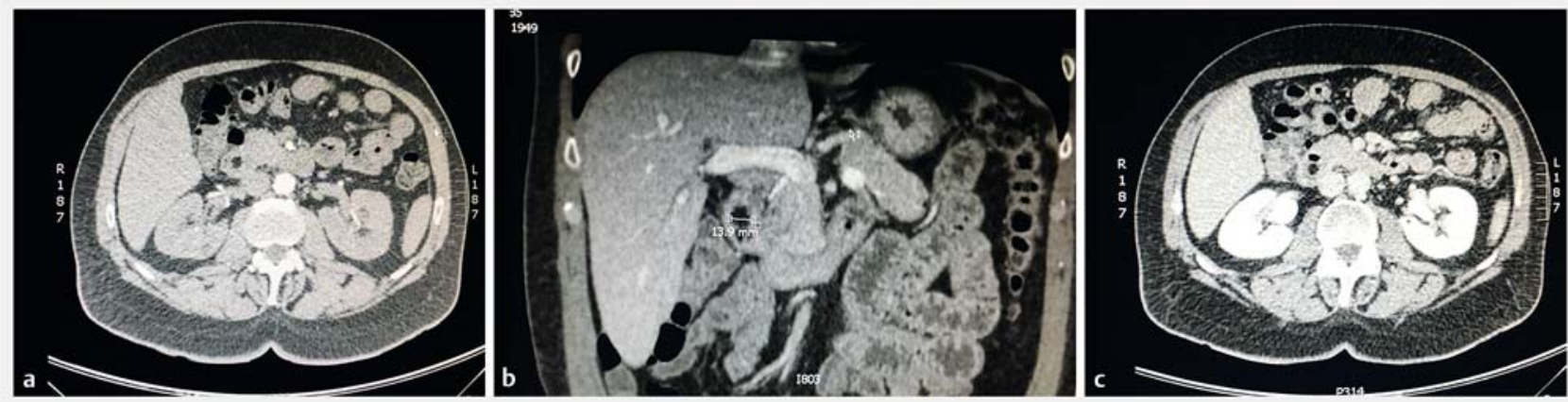

- Fig. 1 Abdominal computed tomography images. a, b A $14 \mathrm{~mm}$, homogeneous, duodenal lesion, with sharp margins and fat density (40-120 Hounsfield units) was identified. c The lesion did not present contrast enhancement.

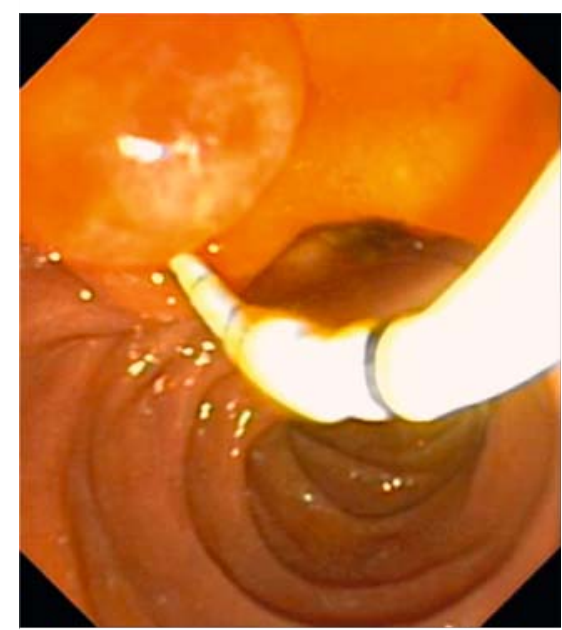

Fig. 2 A yellowish subepithelial lesion of approximately $15 \mathrm{~mm}$ was observed in the second duodenal portion, covering the sphincterotomy opening. (Image shows an occlusion balloon cannulating the common bile duct.)

A 67-year-old Caucasian male was admitted to another institution with choledocholithiasis complicated by acute cholangitis. Endoscopic retrograde cholangiopancreatography (ERCP) showed a large duodenal subepithelial lesion fully covering the papilla, and a dilated common bile duct (CBD) with multiple filling defects. Sphincterotomy was performed and CBD stones were removed. The pa-
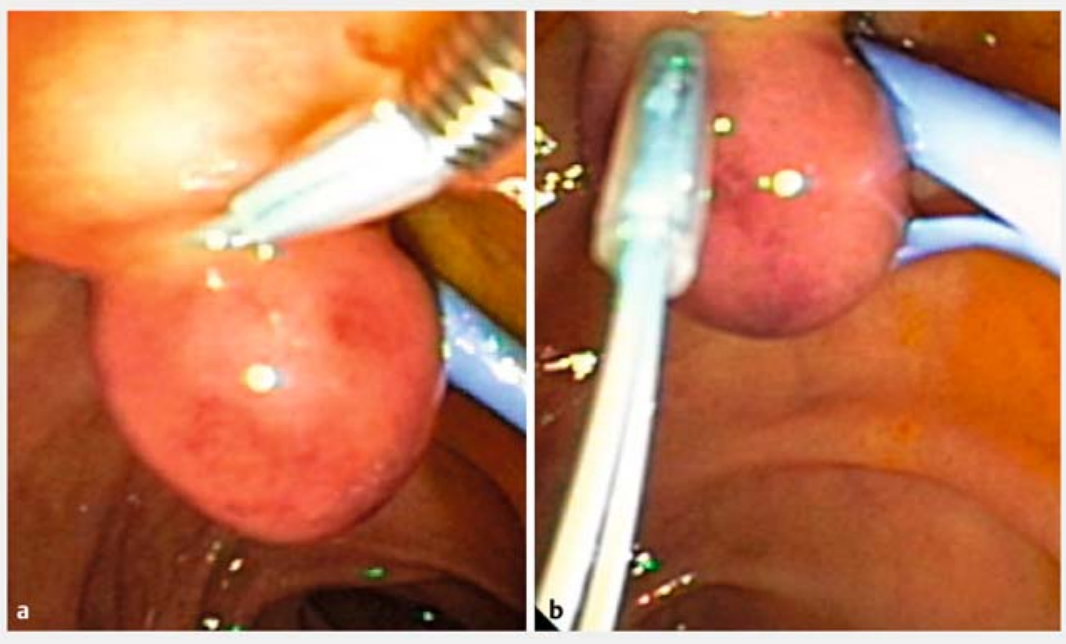

Fig. 3 A biliary plastic stent was temporarily placed to ensure biliary drainage (blue). a The lipoma was then looped and ligated using an Endoloop (Olympus, Tokyo, Japan). b The loop was released when the duodenal lipoma became purplish.

tient underwent laparoscopic cholecystectomy 2 weeks later.

During the subsequent 6 months, he had multiple self-limited episodes of biliary pain. He was admitted twice for this symptom, and on both occasions he underwent ERCP with enlargement of the papillary opening and stone extraction. Abdominal computed tomography (\Fig.1), magnetic resonance cholangiopancreatography, and endoscopic ultrasonography documented a duodenal lipoma, but were otherwise unremarkable. The patient was then referred to our tertiary centre. During a multidisciplinary meeting, he was proposed for endoscopic therapy of the duodenal lipoma, as it was assumed that this was the cause of incomplete biliary drainage. 


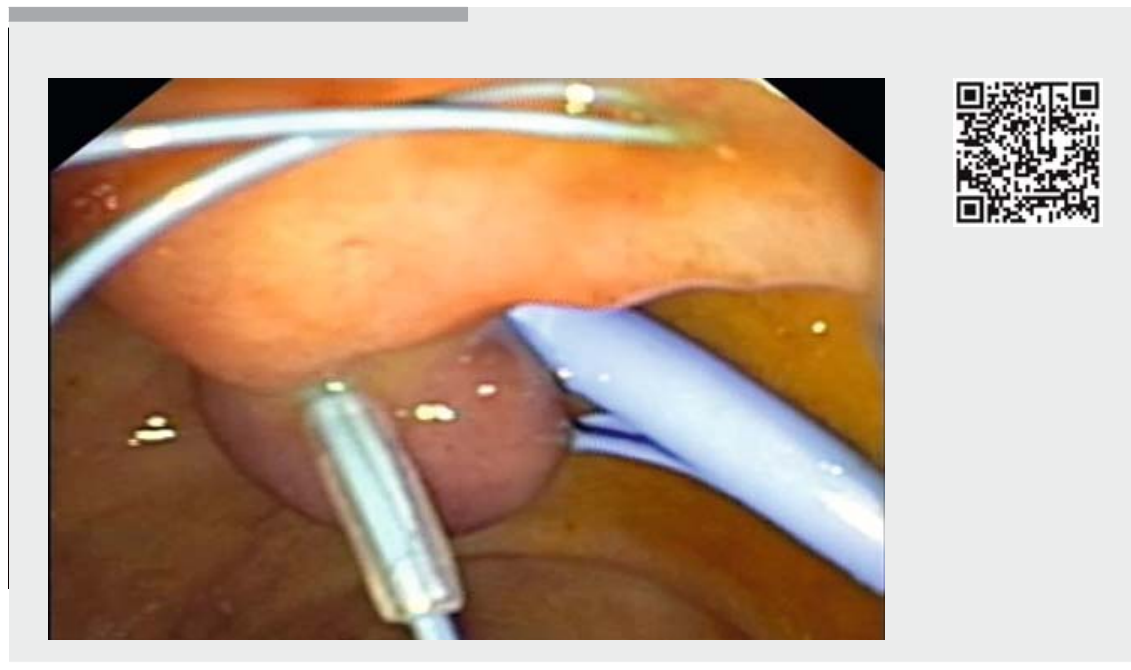

Video 1 Endoscopic treatment of a duodenal lipoma (causing partial biliary obstruction) using the loop-and-let-go technique.

The procedure was performed with the patient in the prone position under deep sedation, with a side-view scope. A yellowish subepithelial lesion of approximately $15 \mathrm{~mm}$ was observed in the second duodenal portion, covering the sphincterotomy opening ( $\bullet$ Fig. 2 ). A biliary plastic stent was temporarily placed to ensure biliary drainage. The lipoma was then looped and ligated with an Endoloop (Olympus, Tokyo, Japan) ( Fig. 3, $\triangleright$ Video 1).

Endoscopic evaluation 3 weeks later showed a periampullary cicatricial area ( Fig.4). The patient remained asymptomatic for more than 6 months after the procedure.

Duodenal lipomas are rare tumors [1]. Only three cases of biliary obstruction caused by duodenal lipomas have been reported [1]. The efficacy of the loopand-let-go technique is well demonstrated in some case series of colonic lipomas [2]. Our case shows the safety and efficacy of this technique in the treatment of a periampullary lipoma - an exceedingly rare lesion. Its usefulness is of paramount importance in the duodenum, as the risk of perforation with snare excision can result in major morbidity.

Endoscopy_UCTN_Code_CCL_1AB_2AZ_3AB

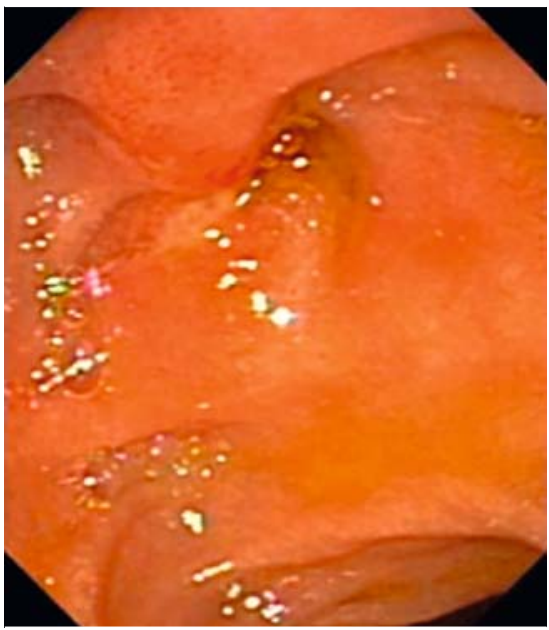

- Fig. 4 A periampullary cicatricial area was observed 3 weeks later on endoscopic re-evaluation.

\section{References}

Competing interests

None

The authors

Joana Carmo', José Rodrigues ${ }^{1}$, Júlio Veloso², Vitor Duarte ${ }^{2}$, Ricardo Gorjão ${ }^{2}$, Eduardo Barroso $^{2}$

1 Serviço de Gastrenterologia, Hospital Egas Moniz - Centro Hospitalar de Lisboa Ocidental, Lisboa, Portugal

2 Centro Hepato-biliopancreático e de Transplantação, Hospital Curry Cabral, Lisboa, Portugal

\section{Corresponding author}

\section{Joana Carmo, MD}

Gastroenterology Department, Hospital Egas Moniz, Centro Hospitalar de Lisboa

Ocidental, Rua da Junqueira, 126, 1349-019

Lisbon, Portugal

Fax: +351-21-3624139

joanavcarmo@gmail.com
[1] Talaat N, Malenie R, Raina A. An unusual case of obstructive jaundice owing to an extra biliary mass. Gastroenterology 2016 151: e8 - e9

[2] Ivekovic H, Rustemovic N, Brkic T et al. Endoscopic ligation ("loop-and-let-go") is effective treatment for large colonic lipomas: a prospective validation study. BMC Gastroenterol 2014; 14: 122

\section{Bibliography}

DOI https://doi.org/10.1055/s-0043-121564

Published online: 14.11.2017

Endoscopy 2018; 50: E34-E35

(c) Georg Thieme Verlag KG

Stuttgart · New York

ISSN 0013-726X

ENDOSCOPY E-VIDEOS

https://eref.thieme.de/e-videos

回回 Endoscopy E-Videos is a free Fection, reporting G: on interesting cases and new techniques in gastroenterological endoscopy. All papers include a high quality video and all contributions are freely accessible online.

This section has its own submission website at https://mc.manuscriptcentral.com/e-videos 